\title{
Electroencephalographic Identifiers of Reading Abilities in Turkish Language
}

\author{
Günet Eroğlu \\ Faculty of Engineering and Natural Sciences \\ Sabanci University, İstanbul, Turkey \\ gunet.eroglu@healthmobilesoftware.com
}

\author{
Müjdat Çetin \\ Faculty of Engineering and Natural Sciences \\ Sabanc1 University, İstanbul, Turkey \\ Dept. of Electrical and Computer Eng., University of Rochester, Rochester, NY, USA \\ mcetin@sabanciuniv.edu
}

\author{
Selim Balcisoy \\ Faculty of Engineering and Natural Sciences \\ Sabanc1 University, İstanbul, Turkey \\ balcisoy@sabanciuniv.edu
}

alone [11]. The findings in the article suggest that IQ tests are not particularly useful for determining learning disabilities. Instead achievement (reading, arithmetic, writing) test scores are more useful diagnostic tools. Learning to read starts with learning the names of the alphabet symbols (rapid automatic naming) and their related sounds (phonological awareness) [1]. The relation between an alphabet symbol and its sound should be unique in order to retrieve the information correctly later on when needed during reading. Reading speed is based on how a person easily retrieves the information about the symbol and its sound(phonics). This reading process involves both shortterm and long-term memory. Both rapid automatic naming and phonological awareness skills have been strongly predictive of individual differences in reading. The performance measure for good reading is, therefore, the reading speed (number of words read in a minute) and the number of errors made during reading. Reading comprehension (which is to understand what is read) develops in the brain after the reading speed reaches a certain level and the vocabulary is extended enough, which requires a variety of oral-language skills [2], [3]. Although IQ is normal or above normal, $5 \%$ of people in many societies may not perform well in reading, writing and/or arithmetic, and/or in learning in general [4], [7]. There is a great deal of research about specific learning disabilities in the literature which show that specific learning disabilities are mostly developmental [12], [13], [24]. The research conducted in this area suggests an abnormal lateralization of prefrontal attentional control processes [22]. This finding is in accordance with the (scarce) evidence that reading disabilities involve a deviant structural asymmetry of the frontal lobe [23]. The recent fMRI studies in neurotypical adults implicate corticostriatal and hippocampal systems in language learning [27]. In the literature, it has been further shown that higher levels of slow brain waves in the Broca area (F7 and FC5) in the left hemisphere have a high correlation with linguistic learning disabilities [5], [6], [10], [21], [25], [26]. These studies have been completed 
using laboratory EEG equipment with 32 or 64 electrodes. In our study, we measured the EEG signals of subjects with a lightweight eMotiv EPOC+ headset with 14 electrodes before , during and after a learning task. The Emotiv EPOC+ headset (http://emotiv.com/) has become one of the leading pieces of BCI equipments available today as a result of its low cost and features, including 14 EEG channels plus two references, inertial sensors, wireless connectivity, the ability to provide raw EEG data as well as averaged EEG data, ease of use and attractiveness for children and adolescents. Although its use for research purposes is being questioned by many researchers, several researches have demonstrated that eMotiv EPOC+ headset captures the EEG data quite accurately [?], [8], [19], [20]. In order to collect data from many children, eMotiv EPOC+ provides a user friendly and ergonomic interface and can integrate with both desktop and mobile phone applications and be used at home. In the near future, with this new technology, it can be possible to apply neurofeedback to young children at home without disturbing them much and without lowering their self-esteem. Turkish is an ortographic language, meaning that the words are read as they are written. This makes the reading easier for many people, yet there are learning disabilities in Turkey. There has been little research [14]-[18] conducted about specific learning disabilities in Turkey and to our knowledge, there is no research conducted about Turkish language which correlates learning disabilities with EEG data. The contribution of this paper is an experimental study that explores neural correlates of reading abilities in Turkish based on EEG data collected by an eMotiv EPOC+ headset. Our experimental analysis of the collected data show that higher slow brain waves in the Broca area (F7 and FC5) in the left hemisphere have a high correlation with linguistic learning disabilities.

\section{MATERIALS \& Methods}

\section{A. Subjects and Experimental data}

Seventeen University students (mean age: 20.58, stddev: $2.39 ; 10$ men, 7 women) are voluntarily participated in this study. All subjects' native language were Turkish.They learned reading without any problem in the elementary school, however they were naive to the alphabet formed with distorted Turkish letters and the computer based training task. Before the experiment, all participants gave their informed consent after the experimental procedure was explained to them in accordance with guidelines set by the research ethics committee. Throughout the experiments, eMotiv EPOC+ headset is used. Internal sampling rate in the headset is 2048 per secs per channel. The data are filtered to remove mains artefacts then down-sampled to 128 per secs per channel. There are 14 EEG channels plus two references. Electrodes were placed according to the 10-20 system. Before the experiments, the calibration of the eMotiv Headset on the subject's scalps is done with the Xavier Control panel of eMotiv, each electrode is made sure to transfer EEG data with high quality (see Figure 1).

\section{B. Study Design}

Participating subjects performed a letter print learning task under simultaneous EEG recordings. The goal of the task was learning the name of new letters which are distorted 180

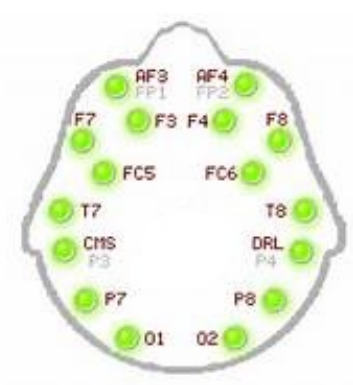

Figure 1: The 10-20 numbering system of eMotiv EPOC electrodes.

degrees in the y-axis (See Figure 1). Before the experiments, the EEG signals in the resting, eyes open state are measured for each subjects for five minutes and the data is stored in .csv files. During these recordings, subjects were placed approximately 0.5 meters in front of a computer screen and instructed to relax with eyes open, looking at a fixation point in the middle of the screen. The programs are written with Python and uses the Community SDK provided by eMotiv to communicate with eMotiv EPOC+ headset. Artefact removal and conversion from Analog to Digital signal is done by the eMotiv standard procedures. libEDK.IEE_GetAverageBandPowers routine is used. During the experiments EEG is recorded, and after the experiment, another five minutes of resting, "eyes open" state EEG signals are recorded.

\section{Letter print learning task}

The task involved showing distorted letters on the screen together with a picture which starts with the letter shown and the phonics of letter (See Figure 2). Throughout the experiments, subjects are shown 29 distorted Turkish letters, repeated three times. In each repetition, there are slight differences in the order of pictures and sounds which are shown on the screen. In the first round, the picture and sound are shown at the same time, in the second round, the picture is shown one second before the sound, in the third round, the picture is shown one second after the sound. This is done for addressing differences in the cross modal attention shift characteristics of different subjects.

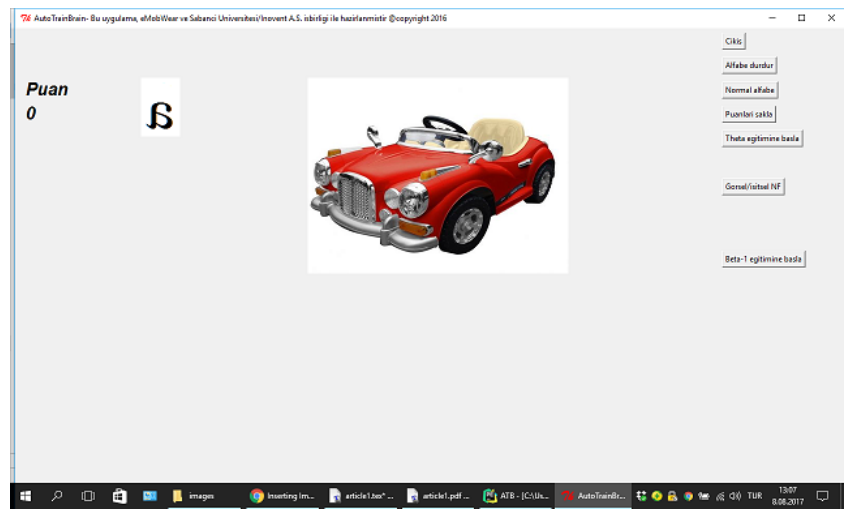

Figure 2: The computer based training program to teach distorted letters. 


\section{Resting-State EEG processing}

For all analyses in this study, all of the 14-channel EEG data are recorded during the experiments in Theta (4-8 Hz), Alpha(8-12 Hz), Beta-1 (12-16 Hz), Beta-2(16$25 \mathrm{~Hz})$, Gamma $(25-45 \mathrm{~Hz})$ bands. As we have used libEDK.IEE_GetAverageBandPowers routine, we have collected averaged and cleaned data from eMotiv EPOC+ headset and used the session average Band powers in our calculations.

\section{E. Measuring performance of reading speed and number of errors}

Before the experiments, subjects are asked to read a text written with distorted letters and their voices are recorded (See Figure 1). The following measures are calculated:

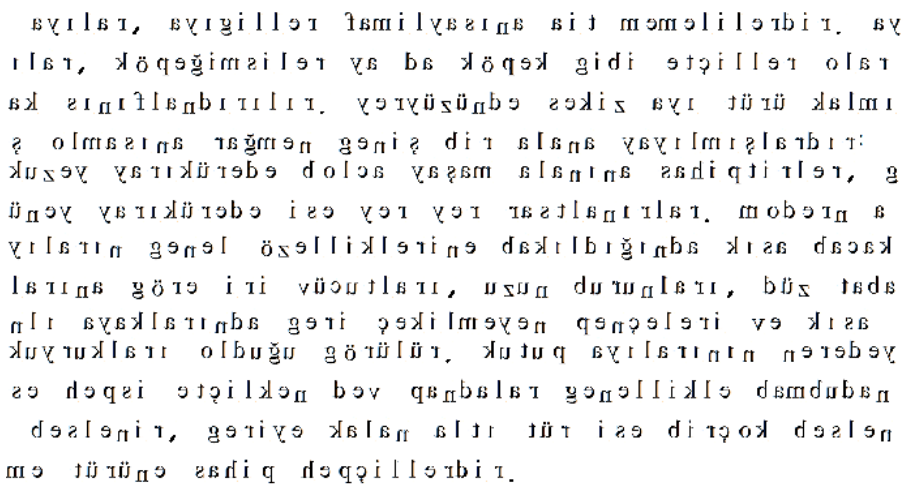

Figure 3: The text written with distorted Turkish letters.

- The number of words read in the first minute ( pretraining)

- The number of errors done (pre-training)

After the experiments, subjects also read another text written with distorted letters and their voices are recorded.

The following measures are calculated.

- The number of words read in the first minute ( posttraining)

- The number of errors done (post-training)

The final performance score is calculated by taking the difference between the post training performance and the pretraining performance.

\section{F. Relation of Resting state Broca Area slow waves with Letter Print learning performance}

Resting state absolute value of Theta brain waves before the experiment have high correlation with the level of letter print learning performance.

\section{G. Analysis of EEG data}

During the EEG recordings, we have excluded the EEG data which exceeded three standard deviatons of the median, as an outlier rejection criterion as onine real time. So the data only had the accepted data as a result of that exclusion. The analysis of data is done with SPSS, and a linear regression model is created. The independent variable is the average of Theta absolute powers at F7 and FC5, the dependent variable is the difference between the correctly read words in one minute after-training and that before training.

\section{RESULTS}

In this research, we investigated whether there is an improvement in reading speed and a decrease in number of errors due to the computer-based training and whether we can correlate the success of training with any characteristic of any EEG brain signals. Based on our analysis of the EEG data collected throughout the experiment, we observed that the frequency modulation across resting states in the Theta at the Broca Area (F7 and FC5) predicts individual reading performance measures. The resting state absolute Theta brain powers at the Broca area (F7 and FC5) before the experiment demonstrated a high correlation (0.66) with the measured learning performance $(\mathrm{P}<0.05)$ (see Figure 4). In order to conclude that a linear regression model is created (the independent variable is the average of Theta absolute powers at F7 and FC5, the dependent variable is the difference between the correctly read words in one minute after-training and that before training) in SPSS. The output of regression model is compared with the actual data using ANOVA. The result is statistically significant $(\mathrm{P}<0.05)$ and the correlation coefficient is 0.66 (see table 1 and table 2).

In other words, the slower the brain waves measured in the Broca area (F7 and FC5) at resting state, the less useful the computer based training of distorted letters is for learning performance.

\section{CONClusion}

In this research, we have confirmed using eMotiv EPOC+ headset that the resting state absolute Theta brain powers at the Broca area (F7 and FC5) determines the reading abilities. In our future research, we will be using the results found in this research in order to create a specific neurofeedback protocol for enhancing reading abilities of dyslexic people who have learning disability and we will plan to apply this specific neurofeedback protocol on dyslexic subjects more than 20 times to see whether there will be any improvement in their reading abilities.

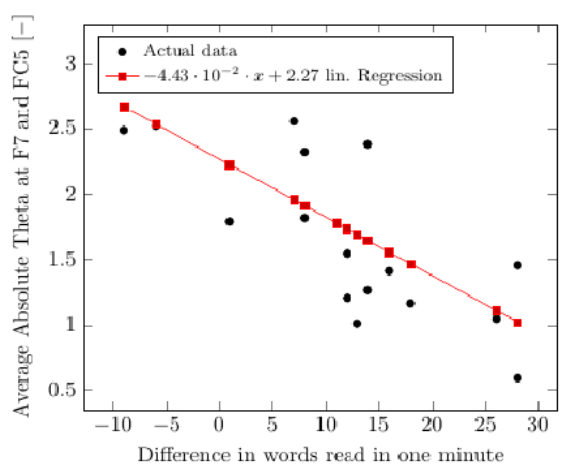

Figure 4: Words read versus Absolute Theta at Broca before the experiment 
TABLO I: Learning performance measures

\begin{tabular}{llllllll}
\hline ID & Agc & Sex & error pre-training & error post training & Oneminute-pre & Oneminutc-post & Words read one minute \\
\hline 307 & 19 & Male & 3 & 14 & 40 & 28 \\
304 & 19 & Female & 3 & 2 & 49 & 75 & 28 \\
5000 & 20 & Male & 4 & 1 & 42 & 65 & 26 \\
505 & 18 & Femalc & 7 & 1 & 18 & 31 & 18 \\
5002 & 20 & Female & 6 & 5 & 31 & 46 & 16 \\
302 & 22 & Female & 4 & 2 & 24 & 36 & 14 \\
5006 & 20 & Male & 0 & 2 & 0 & 16 & 14 \\
5004 & 19 & Male & 4 & 2 & 25 & 36 & 13 \\
2002 & 20 & Male & 4 & 1 & 31 & 40 & 12 \\
5009 & 20 & Male & 3 & 0 & 31 & 40 & 12 \\
5001 & 20 & Female & 7 & 5 & 42 & 51 & 11 \\
308 & 18 & Male & 0 & 0 & 30 & 38 & 8 \\
303 & 27 & Female & 3 & 2 & 49 & 56 & 8 \\
5003 & 20 & Male & 3 & 3 & 45 & 52 & 7 \\
2001 & 25 & Male & 1 & 3 & 37 & 40 & 1 \\
306 & 20 & Male & 1 & 0 & 50 & 43 & -6 \\
301 & 23 & Female & 2 & 2 & 43 & 32 & -9 \\
\hline
\end{tabular}

TABLO II: Theta powers at Broca area

\begin{tabular}{lllll}
\hline ID & Words read in one minute & Avg Theta (F7) & Avg Theta(FC5) & Average of Theta at F7 and FC5 \\
\hline 307 & 28 & 1,346621 & 1,564475 & 1,455548 \\
304 & 28 & 0,821042 & 0,352808 & 0,586925 \\
5000 & 26 & 1,233911 & 0,860058 & 1,0469845 \\
5005 & 18 & 0,75083 & 1,582611 & 1,1667205 \\
5002 & 16 & 2,077955 & 0,746231 & 1,412093 \\
302 & 14 & 0,440884 & 2,090648 & 1,265766 \\
5006 & 14 & 2,873486 & 1,878642 & 2,376064 \\
5004 & 13 & 1,463205 & 0,562709 & 1,012957 \\
2002 & 12 & 1,038742 & 1,374948 & 1,206845 \\
500 & 12 & 2,15392 & 0,934102 & 1,544011 \\
5001 & 11 & 3,149928 & 2,957646 & 3,051287 \\
308 & 8 & 1,571115 & 2,060929 & 1,816022 \\
303 & 8 & 2,549321 & 2,086834 & 2,3180775 \\
5003 & 7 & 3,630647 & 1,46787 & 2,549252 \\
2001 & 1 & 0,915747 & 2,660747 & 1,788247 \\
306 & -6 & 3,537321 & 1,495707 & 2,516514 \\
301 & -9 & 2,6577 & 2,307136 & 2,482418 \\
\hline
\end{tabular}

\section{REFERENCES}

[1] Torgesen, Joseph K., et al. "Contributions of phonological awareness and rapid automatic naming ability to the growth of word-reading skills in second-to fifth-grade children." Scientific studies of reading 1.2 (1997): 161-185.

[2] Geva, Esther, and Linda S. Siegel. "Orthographic and cognitive factors in the concurrent development of basic reading skills in two languages." Reading and Writing 12.1 (2000): 1-30.

[3] Dickinson, David K., et al. "The comprehensive language approach to early literacy: The interrelationships among vocabulary, phonological sensitivity, and print knowledge among preschool-aged children." Journal of Educational Psychology 95.3 (2003): 465.

[4] Siegel, Linda S. "IQ is irrelevant to the definition of learning disabilities." Journal of learning disabilities 22.8 (1989): 469-478.

[5] Spironelli, Chiara, Barbara Penolazzi, and Alessandro Angrilli. "Dysfunctional hemispheric asymmetry of theta and beta EEG activity during linguistic tasks in developmental dyslexia." Biological psychology 77.2 (2008): 123-131

[6] Duffy, Frank H., et al. "Dyslexia: Regional differences in brain electrical activity by topographic mapping." Annals of neurology 7.5 (1980): 412420.

[7] Hallahan, Daniel P. "Some thoughts on why the prevalence of learning disabilities has increased." Journal of Learning Disabilities 25.8 (1992): 523-528

[8] Ekanayake, H. (2010). "P300 and Emotiv EPOC: Does Emotiv EPOC capture real EEG?" Retrieved from: http://neurofeedback.visaduma.info/emotivresearch.htm

[9] Ozdenizci, Ozan, et al. "Electroencephalographic identifiers of motor adaptation learning." Journal of Neural Engineering (2017).

[10] Gitelman, Darren R., et al. "Language network specializations: an analysis with parallel task designs and functional magnetic resonance imaging." Neuroimage 26.4 (2005): 975-985.

[11] D'Angiulli, Amedeo, and Linda S. Siegel. "Cognitive functioning as measured by the WISC-R: Do children with learning disabilities have distinctive patterns of performance?." Journal of Learning Disabilities 36.1 (2003): 48-58.

[12] Ross, Gail, et al. "Effects of mothers' autoimmune disease during pregnancy on learning disabilities and hand preference in their children." Archives of pediatrics and adolescent medicine 157.4 (2003): 397-402.

[13] Wood, Lawrence C., and David S. Cooper. "Autoimmune thyroid disease, left-handedness, and developmental dyslexia." Psychoneuroendocrinology 17.1 (1992): 95-99.
[14] KORKMAZLAR-ORAL,Umran. "OGRENME SORUNLARINI ERKEN TANIMAK." CEREBRAL PALSY SYMPOSIUM V.

[15] Korkmazlar, Ü. "6-11 yas ilkokul cocuklarinda ozel ogrenme bozuklugu ve tani yontemleri" Doktora Tezi, İstanbul Üniversitesi Tip Fakültesi, İstanbul (1992).

[16] Karaman, D., T. Turkbay, and F. S. Gokce. "Ozgul ogrenme bozuklugu ve dikkat eksikligi hiperaktivite bozuklugu binisikliginin bilissel ozellikleri." Cocuk ve Genclik Ruh Sagligi Dergisi 13.2 (2006): 60-8.

[17] KARAMAN, Dursun, Koray KARA, and İbrahim DURUKAN. "OZGUL OGRENME BOZUKLUGU." Anatolian Journal of Clinical Investigation 6.4 (2012).

[18] Bamidis, Panagiotis, John Gruzelier, and Ana Vivas. "SAN 2011 MEETING PROGRAM."

[19] Liu, Yue, et al. "Implementation of SSVEP based BCI with Emotiv EPOC." Virtual Environments Human-Computer Interfaces and Measurement Systems (VECIMS), 2012 IEEE International Conference on. IEEE, 2012.

[20] Mayaud, Louis, et al. "A comparison of recording modalities of P300 event-related potentials (ERP) for brain-computer interface (BCI) paradigm." Neurophysiologie Clinique/Clinical Neurophysiology 43.4 (2013): 217-227. bibitemBou Boutani, Hidenori, and Mieko Ohsuga. "Applicability of the "Emotiv EEG Neuroheadset" as a user-friendly input interface." Engineering in Medicine and Biology Society (EMBC), 2013 35th Annual International Conference of the IEEE. IEEE, 2013.

[21] Papagiannopoulou EA, Lagopoulos J. Resting State EEG Hemispheric Power Asymmetry in Children with Dyslexia. Frontiers in Pediatrics. 2016;4:11. doi:10.3389/fped.2016.00011.

[22] Wijers, Albertus A., Pieter H. Been, and Koos S. Romkes. "Dyslexics show a deviant lateralization of attentional control: a brain potential study." Neuroscience letters 374.2 (2005): 87-91.

[23] Hugdahl, Kenneth, and Richard J. Davidson, eds. The asymmetrical brain. MIT press, 2004.

[24] Kang, D.-H., Davidson, R. J., Coe, C. L., Wheeler, R. E., Tomarken, A J., Ershler, W. B. (1991). Frontal brain asymmetry and immune function. Behavioral Neuroscience, 105(6), 860-869.

[25] Sangal, R. Bart, and JoAnne M. Sangal. "Use of EEG beta-1 power and theta/beta ratio over Broca's area to confirm diagnosis of attention deficit/hyperactivity disorder in children." Clinical EEG and neuroscience 46.3 (2015): 177-182.

[26] Lubar, Judith O., and Joel F. Lubar. "Electroencephalographic biofeedback of SMR and beta for treatment of attention deficit disorders in a clinical setting." Applied Psychophysiology and Biofeedback 9.1 (1984): $1-23$.

[27] Saloni Krishnan, Kate E.Watkins, Dorothy V.M.Bishop ."Neurobiological Basis of Language Learning Difficulties" CellPress Volume 20, Issue 9 (2016). 